\title{
Business strategy and marketing: the positioning versus resource-based dichotomy and the way forward
}

\author{
H. Oosthuizen* \\ Graduate School of Business, University of Stellenbosch \\ PO Box 610, Bellville 7535, Republic of South Africa \\ ho2@usb.sun.ac.za
}

Received September 2002

\begin{abstract}
This paper explores the relationship that exists between business strategy and marketing strategy and how the latter may contribute towards the development of an integrated and systemic approach to organisation-wide strategy development. It finds that the two broad streams in strategy, namely positioning-based and resource-based have a reciprocal relationship and indeed complement each other. The link between business strategy and functional strategies, however, is unclear, particularly in the case of marketing strategy. This uncertainty is mainly attributable to the consideration that marketing strategy appears to be frozen within either a positioning or resource-based view. In this regard a conceptual framework has been proposed which combines the two business approaches into one integrated marketing mission approach. As such the marketing function performs a facilitating role in the formulation of overall organisational strategy in an integrative fashion.
\end{abstract}

*To whom all correspondence should be addressed.

\section{Introduction}

Competitive advantage and gaining above industry-average output performance is at the very heart of both business and marketing strategies. Nevertheless, there appears to be a dearth of authenticated information connecting these two strategy levels and, furthermore, much of what is available could be considered fragmented, i.e. addressing selected parts but never giving the total perspective. It is thus the purpose of this paper to:

1. Explore the links between the classical positioningbased view (PBV) and the resource-based view (RBV) of business strategy and to emphasise the formulation of a strategy in an integrative mode.

2. Investigate the links and relationships between business strategy and functional strategies, and in particular marketing strategy.

3. Develop and outline a conceptual framework that makes explicit and integrates the various strands of business and marketing strategies into a framework.

The plan of the paper is, first to explore the approaches to business strategy formulation, secondly to describe the importance of functional units, particularly marketing and, finally, to propose a framework for an integrative analysis of business and marketing strategies. A summary is provided as well as a conclusion and a look at the way forward. The main body of the paper is depicted in Diagram 1 below.

It should be noted that integrative frameworks may try to encompass everything and eventually explain very little.
The framework outlined in this paper may probably also suffer from this 'theory-of-all-trades' syndrome. Nevertheless, it is hoped that it offers some useful insights and provides a common ground for further development.

\section{Approaches to business strategy formulation}

\section{Background - Strategy development}

The fundamental question in the field of strategic management is how organisations achieve and sustain competitive advantage ( Teece, Pisano \& Shuen, 1997:509) and thus attain above industry-average profits, i.e. what is the basis for the development and formulation of a strategy? In this paper the focus is on two managerially oriented approaches and their possible linkages. These two broad approaches, to be outlined below, are considered to be differentiated more by epistemological differences than by chronological order.

From the 1950s, when the subject of strategic management started to emerge as a distinct specialism, the external environment was regarded to be the primary determinant of strategy (Hitt \& Ireland, 1985:273). This classical view, which has its origin in the industrial organisation tradition, became known as the Industry-Organisation (I/O) model, outside - in model or market-based view. Over time, this basic framework of analysis has been elaborated on and improved by a number of authors. Among these, the single most important contributor has probably been Michael Porter (1985) with his development and formalisation of the positioning-based view (PBV). 


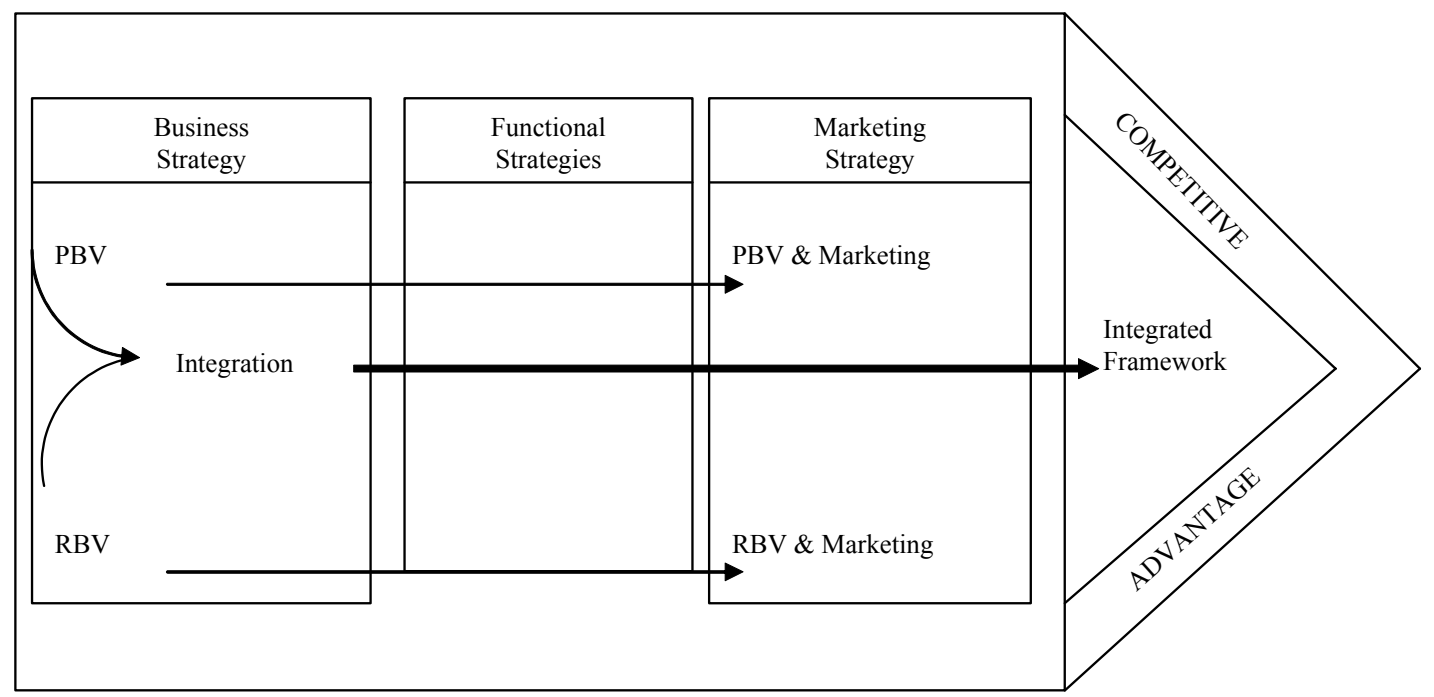

Diagram 1: Plan of paper

However, at about the same time during the mid-eighties (Wernerfelt, 1984), and, albeit in relative obscurity at the time, the resource-based view (RBV) of competition also started to emerge (Gagnon, 1999:125), in contrast to the market-based view. According to this model the organisation's resources and capabilities should be the starting point or primary determinant for strategy formulation and, thus, precede the positioning decisions. This inside-out view gained major support and popularity since Prahalad and Hamel (1990) emphasised the link between core competencies and competitiveness. Recent research, however, suggests that the PBV and RBV are not separate (Juga, 1999:16) but that there is a reciprocal relationship between the external environment and the organisation's resources, and that it is this interrelationship that affects the organisation's performance.

In the subsequent three sections the PBV and RBV will be discussed, as well as the interaction between the two approaches. It should be emphasised that any approach to strategy formulation is aimed at achieving a sustainable competitive advantage. For the purposes of this paper it is defined as: 'A firm is said to have a sustained competitive advantage when it is implementing a value creating strategy not simultaneously being implemented by any current or potential competitors and when these other firms are unable to duplicate the benefits of this strategy' (Barney, 1991:102).

It should be mentioned that other prominent streams of strategic thought have been identified, namely capability logic, guerilla logic and complexity logic (Lengnick-Hall \& Wolff, 1999). They broadly relate to the RBV (capability logic) and the PBV (guerilla logic \& complexity logic) and will not be further elaborated upon in this paper.
The positioning-based view - A brief critique of the conventional approach as a dominant framework

\section{Introduction}

Positioning represents the conventional or classical view of strategy formulation and is well researched and documented. As such only a relatively brief review will suffice for the purposes of this paper.

In classical strategy literature the notion of competitive advantage is mostly attributed to management's ability to continuously position the organisation's assets against some external context, hence the reference to Contingency Theory (Homberg, Workman \& Krohmer, 1999:2). Therefore, the structure of and changes within the competitive environment are of overwhelming importance and a strategy for delivering competitive advantage will be the one that best positions the organisation within the environment. The major aim of strategic management is thus deemed to secure the organisation's effectiveness by doing the right things, rather than efficiency by doing things right. Various portfolio frameworks and matrices have been developed for visualising the strategic positioning task, usually reflecting the organisation's competitive position relative to industry attractiveness. The idea of creating a match or fit with the external environment is central in the classical strategy literature (Juga, 1999:4). Three leading proponents of the PBV are considered to be Miles and Snow (1978), Porter (1985), and Covin (1991).

\section{The Miles and Snow typologies}

Several appropriate strategic typologies of organisations under different external conditions have been developed in the strategic management and organisational behaviour literature (McDaniel \& Kolari, 1987:20). The Miles and Snow typology (1978), however, is unique because it views 
the organisation as a complete and integrated system in dynamic interaction with its environment, '... every organization is embedded in a network of external influences and relationships which can be labelled as its environment' (Miles \& Snow, 1978:18). These environmental influences may be classified into four factors, namely market characteristics, technology, competition and business' relative strengths to competitors (Boyd, Walker \& Larréche, 1998:221).

Miles and Snow postulate that competing organisations exhibit patterns of behaviour representative of four basic strategic types, namely Defenders, Prospectors, Analyzers and Reactors (Miles \& Snow, 1978:29). The key dimension underlying this typology is which environmental situation is most amenable to the successful pursuit of each type of strategy? For example, a Prospector strategy is considered to be particularly well-suited to unstable, rapidly changing environments resulting from new technology, shifting customer needs, or both. The Defender strategy, on the other hand, is most appropriate for businesses in relatively mature, stable industries. The Analyzer strategy is considered to be most appropriately matched to emerging industry conditions (Forte, Hoffman, Lamont \& Brockman 2000:769), whilst the Reactor lacks any well-defined strategy that could be linked to any set of external circumstances.

\section{Porter's generic strategies}

It was Porter (1985) who articulated the meaning of competitive advantage as the ability to manage value chain activities in such a way as to achieve one of two generic strategies, namely Low Cost and Differentiation, with the option to pursue either or both (best-cost) at a broad or focused level.

A cost leadership strategy aims to provide goods or services at the lowest cost, relative to that of competitors, with features that are acceptable to customers. This strategy, often coupled to low price, is best employed in a market or segment (external environment) where demand is price elastic (Campbell, Stonehouse \& Houston, 2000:136). Other external environmental conditions will obviously also direct this choice of strategy (Thompson \& Strickland, 2001:161-162).

A differentiation strategy is designed to create output that customers perceive as being different and unique in ways that are important and valuable to them. It applies best in an external environment where buyer needs and uses are diverse and there are many possible ways to differentiate the product or service (Thompson \& Strickland, 2001:166-167).

\section{Covin's strategic postures}

Another way of describing the concept of strategic posture is to view this as an organisation's placement along a continuum ranging from conservative to entrepreneurial (Covin, 1991:439). Organisations with conservative strategic postures are risk-averse, non-innovative, and reactive. Organisations with entrepreneurial strategic postures are risk-taking, innovative, and proactive. It is considered that the entrepreneurial posture is more suited to emerging, turbulent or high velocity external conditions whilst the conservative posture relates best to maturing, stagnant and declining external conditions.

\section{Summary}

It may be said that organisations comprise of collections of discrete but interrelated socio-economic activities, and that their strategies describe the configuration of these activities in relation to particular environmental conditions. To understand these patterns three distinct strategic typologies have emerged, i.e. Miles and Snow, Porter and Covin.

These typologies should not be seen as fragmented and incompatible but indeed form a synthesised combination. This becomes clear when it is considered that each one of the typologies is clearly associated with two core characteristics (Waldersee \& Sheather, 1996:108). The first characteristic emphasises the innovative aspects of organisational activity and is commonly referred to as a Prospector (Miles \& Snow), Differentiator (Porter), or Entrepreneurial (Covin). The second characteristic underlying the different typologies emphasises stability. Organisations pursuing the Defender (Miles \& Snow), Low Cost (Porter) or Conservative (Covin) approaches aim to achieve cost leadership through an advantage such as tight cost control in stable areas. They aim at locating and maintaining secured niches in relatively stable product areas by producing higher quality, superior service, or lower prices. They have concern for asset use, employee productivity, and discretionary expenses (Segev, 1989:493).

Because of the close proximity of the various typologies, as outlined above, as well as the fact that these approaches are considered to be a unit by their Newtonian mechanistic logic (Farjoun, 2002:561), the terms business strategy and competitive strategy are used interchangeably in this paper.

\section{PBV and its challenges}

The main challenges or shortcomings of the PBV are considered to be the following:

- The late 1980s and 1990s experienced increased external complexity caused by high interest rates, obstreperous trade unions, impatient investors, as well as political and social deconstruction. This context led to the belief that it is difficult, if not impossible, to continuously find the most advantageous position for the organisation in relation to its ever-changing environment (Oosthuizen, 2000:11).

- Positioning models assume that organisations within an industry are identical (homogeneous) in terms of their strategically relevant resources (Barney, 1991:100).

- Positioning models assume that should resource heterogeneity develop in an industry, this heterogeneity will be very short- lived because the resources that organisations use to execute their strategies are highly mobile, i.e. can easily be bought and sold (Barney, 1991:100). 
The above-mentioned three problems are deemed to be overcome by the resource-based view, which is discussed in the next section.

The resource-based view - A different perspective for strategy formulation

\section{Introduction}

'Resource-based research is a fairly young stream, which started generating a significant amount of output only in the early 1990s' (Stockport \& Chaddad, 2001:15). Within the field of strategic management, the term 'resource-based' indicates a focus on the internal set of resources and capabilities that an organisation can utilise to create and support competitive advantage. Decisions in this regard should precede the external positioning decision, i.e. resource-based attributes enable the choice of a particular positioning strategy.

The RBV is considered to be more appropriate than the PBV in a turbulent environment (Long \& Vickers-Koch, 1995:418) with ever-changing market boundaries because 'it provides potential access to a wide variety of markets' (Prahalad \& Hamel, 1990:83). As such the RBV favours short-term strategic alliances over more permanents $M$ \& A's (Das \& Teng, 2000:36). Furthermore, the RBV substitutes two alternate assumptions to those made by the PBV. First, it assumes that organisations within an industry may be heterogeneous with respect to the strategic resources they control. Secondly, the RBV model assumes that these resources may not be perfectly mobile across organisations, and thus heterogeneity can be long lasting (Priem, 2001:64).

A brief historical overview of the development of the RBV is given in the next section followed by an analysis of its content (section iii) and a review of the state-of-the art of the RBV. It concludes with a short discussion of the interaction between PBV and RBV. In perusing these it should be remembered that there is as yet limited agreement on the terminology to be employed (Rugman \& Verbeke, 2002:770) and similar terms are often used interchangeably by different authors (Marsden, 1998:35). Terms are badly blurred in practice (Peng, 2001:823) and the RBV generally suffers from 'imprecise definitions' (Priem, 2001:57). Despite the confusing terminology, however, it is possible to describe the main characteristics of what is known as the RBV.

\section{Historical overview}

'There is nothing new under the sun' (Peters \& Waterman, 1982:117) and it appears that the concept of 'distinctive competence' was first used in 1957 by Philip Selznick in his book 'Leadership and Administration' (Peters \& Waterman, 1982:98). This term was described as 'what a particular company is uniquely good at, and most others are not' (Peters \& Waterman, 1982:98). Thus developed relative internal strengths and weaknesses. Ansoff (1965:94-99) was the first to analyse from this particular perspective and therefore audited the resources of the organisation. Building on Ansoff's work, Andrews (1971:37) further developed the idea of strengths and weaknesses and proposed the idea of a corporate competence or strength which was defined as an ability that will attract customers away from the competition. In contemporary writings it is emphasised that a strength should refer to a resource, rather than a source, the latter only being valuable when it is applied or utilized (Barney, 1991:106; Valentin, 2001).

In 1984, Wernerfelt's seminal article entitled 'A resourcebased view of the firm', established a watershed in strategic thinking when it stated that organisations should be analysed 'from the resource side rather than from the product side' (Wernerfeldt, 1984:171). The remainder of the 1980s was punctuated with sporadic articles on RBV concepts. Noteable were Rumelt (1984) who refers to 'isolating mechanisms' to describe resources that protect organisations from imitations (Stockport \& Chaddad, 2001:3), and Dierckx and Cool (1989) who explored competitive advantage from the perspective of 'resource accumulation'.

The well-known 1990 article by Prahalad \& Hamel entitled 'The core competence of the corporation', popularised the RBV research stream and it became known as such. During the 1990's resource-based research started to focus less on core concepts and look more at specific implementations of the concept, e.g. information (Pollalis \& Grant, 1994) and employee motivation (Collis \& Montgomery, 1995). By 2001 authors like Priem (2001) started to question and critically evaluate the RBV as a theoretical system as well as its potential contribution to strategic management. Rouse and Daellenbach (2002:963) note that, '... a number of articles have begun to debate the theoretical underpinnings of the RBV'.

\section{$\mathrm{RBV}-\mathrm{An}$ analysis of content}

An analysis of RBV content comprises three aspects, namely resources, sources of output - capabilities and competencies, and measuring impact, or output performance.

\section{(aa) Resources}

Resources include any type of asset controlled by an organisation that enable that organisation to conceive of and implement strategies that improve its efficiency and effectiveness (Barney, 1991:101).

Since organisational resources are of many types, it is no surprise that scholars have proposed a plethora of resource typologies e.g. physical, human and organisational, financial, technological, physical, managerial, propertybased and knowledge-based, etc. It is, however, generally accepted (Stockport \& Chaddad, 2001:7) that resources can be tangible (e.g. human, financial and physical) or intangible (e.g. brand names, patents and legal rights); they can also be internal to the organisation (e.g. patent rights) or external to the organisation (e.g. social ties to government agencies). Intangible resources may furthermore be subdivided into complementary resources (e.g. culture and reputation) and underlying capabilities (Oosthuizen, 2000:10).

Resources cannot be evaluated in isolation, because their value is determined in the interplay with external market 
forces. There is no competitive advantage in having a resource that is unique but has little value, for example, in having the most antiquated computer system in the industry (Medcof, 2000:61). The potential for sustainable competitive advantage comes from resources whose value and uniqueness are intrinsically more enduring than those of other organisations. To have this potential, an organisational resource must pass a number of external market tests (isolating mechanisms) of its value (Collis \& Montgomery, 1995:120-122):

- The test of inimitability - Is it hard to copy?

- The test of desirability - How quickly does this resource depreciate?

- The test of substitutability - Can a unique resource be trumped by a different resource?

- The test of superiority - Whose resource is realty better?

The lesson for managers is that decisions about critical internal resources (efficiency) should be based upon data from the external market-place (effectiveness).

(bb) Sources of output - capabilities and competencies

Sources of competitive output performance is vested in capabilities and competencies (Rouse \& Daellenbach, 2002:966)

Capabilities is the organisation's capacity to integrate its portfolio of resources to perform value chain activities and achieve a desired output performance. Capabilities are manifested in such typical business activities as order fulfillment, new product development, and service delivery (Day, 1994:38). Capabilities may be developed in any of the functional (primary) or support activities of the traditional value chain (Amit \& Schoemaker, 1993:35) and constitute strategic routines with a predictable outcome. However, in high-velocity markets, they adopt the role of dynamic capabilities that redirect, or alter, the resource-base into a new configuration in order to generate new valuecreating competitive advantages (Eisenhardt \& Martin, 2000:1107).

Simultaneous with the rising interest in the RBV during the 1990s, the concepts of re-engineering (Hammer \& Champy, 1993) and business processes (Johansson, McHugh, Pandlebury, \& Wheeler, 1993) came to the fore. These concepts proposed new ways of creating value-chain improvements and looked at internal resources and business processes as a set of value-chain activities that crosses function boundaries, an idea that was proposed as early as 1961 (Fish, 1961). The concept of a 'revamped' value chain emerged, and was in essence redefined by Porter, to be termed an Activity System (Porter, 1996:73). In this framework an organisation's strategic position is viewed as a system comprising of sets of tailored activities (processes) designed to deliver higher-order strategic themes (competence/core competence/distinctive competence).
These terms may be defined as follows (Oosthuizen, 2000:11):

- A competence is an internal value-chain process that an organisation performs better than other internal processes.

- Activities and processes that do not constitute part of a competence, may be outsourced.

- A core competence is a well-performed internal process that is central to the organisation's strategy, e.g. Honda's ability to 'miniaturise' engine technology. Non-core activities and processes are peripheral and may be outsourced.

- A distinctive competence is a competitively valuable core competence that an organisation performs better than its rivals. A distinctive competence (Honda engine) is embodied in the end-product (Honda car) and provides unique value-added benefits to the buyer. It results in above industry average profitability for the organisation.

It should be clear that capabilities and competencies are the glue that brings resources together and enables them to be deployed advantageously. They cannot be given a monetary value and are deeply embedded in organisational routines and practices. For this reason they are mainly based on developing, carrying, and exchanging information and knowledge through the organisation's human capital. An organisation's sustainable competitive advantage thus derives from knowledge, know-how, intellectual assets, etc. - known as complementary assets - and are firmly embedded in the people working for a particular organisation. This situation leads to causal ambiguity, which is ambiguity about the link between organisational resources and sustained competitive advantage, and protects the organisation from competitive imitation, i.e. the difficulty competitors might experience in identifying how an advantage was created in the first place (King \& Zeithaml, 2001:76).

\section{(cc) RBV and output performance}

High-performing organisations should be the focus of RBV research and, as a result, 'performance should feature as a selection variable' (Rouse \& Daellenbach, 2002:966). The following paragraphs provide a brief overview of the relationship between RBV and output performance.

Economists commonly distinguish among three types of rent, namely Ricardian rents that are extraordinary profit earned from resources that are in fixed or limited supply; Pareto rents (or guasi rents) that refer to the difference between the payments to a resource in its best and second best use; and Monopoly rents that stem from collusion or government protection (Amit \& Schoemaker, 1993:34). The RBV emphasises the importance of organisation - specific factors (resources) in explaining economic rent (Peteraf, 1993:180), i.e. the concept of relative resource scarcity is tied to the idea of resource superiority (Castanias \& Helfat, 1991:161). For example, office space in Manhattan 
generates Ricardian rents because it is scarce. Furthermore, it is scarce largely because land in Manhattan is scarce, inimitable, and resistant to substitution (Valentin, 2001:57).

The previous paragraph has centered on the performance of organisation specific resources under particular or given circumstances. However, because the RBV is fundamentally concerned with the accumulation of assets (Peteraf, 1993:188), it relates naturally to output performance considerations regarding the boundaries or scope of the organisation through $\mathrm{M} \& \mathrm{~A}$ activity, diversification, collaboration and other forms of boundaryredefinition. In fact, the prevailing view of strategic (related) diversification can be characterised as a fit of resource-based benefits within the value chain (Thompson \& Strickland, 2001:292).

Furthermore, organisations with generalisable resources have a much wider opportunity set in being able to access a variety of markets, thus sustaining and improving output performance. This is particularly important in a turbulent environment and where a blurring of boundaries occurs. Clearly the RBV has implications for various aspects regarding corporate strategy and in this regard it has been referred to as constituting a 'resource portfolio' (Clark \& Brennen, 1998:128).

\section{RBV - State of the art}

An investigation into resource-based research from 1984 to 2000 concluded that it is still a fairly young stream and has yet to break into the world of managers (Stockport \& Chaddad, 2001:15). As major reasons for this it cites an amphasis on theory-building rather than theory testing, the use of secondary rather than primary data, and the use of qualitative approaches. These views are endorsed by various authors:

- 'One challenge arises because the empirical evaluation of the RBV is still in its infancy ...' (Medcof, 2000:66).

- $\quad$ 'Our difficulty in testing resource-based propositions suggests limitations to the theory's practicality' (Poppo \& Weigelt, 2000:585).

- 'Although some theorists suggest that the resourcebased view could be a new theory of the firm, it is still part of a developing paradigm in strategy research. The usefulness and richness of the paradigm need to be demonstrated in a variety of strategy areas' (Das \& Teng, 2000:32)

- 'The RBV does not presently appear to meet the empirical content criterion required of theoretical systems' (Priem, 2001:34).

- ' ... the field can still be considered as lacking maturity, ...' (Rugman \& Verbeke, 2002:770).

In summary, it would appear that the RBV hasn't yet developed clear and generally accepted strategic typologies. Furthermore, specific gaps in the RBV research direction have been suggested with regard to inter alia entrepreneurship and marketing (Barney, Wright \& Ketchen, 2001), and in deregulated (privatised) industries (Pettus, 2001). All of these aspects have particular applicability to South Africa; yet, a search on the Sabinet data-base (June 2002) revealed that nothing relating to RBV, or any application thereof, has been published in this country during the past 15 years.

\section{Interaction between PBV and RBV}

On the surface it would appear that a tautology exists in the PBV versus the RBV, i.e. it is either the one or the other. However, increasingly it is being realised that together these two views constitute the major underlying effects of the variance in organisational profitability (McGahan \& Porter, 1997:23). A current stream of research findings confirms this, and for illustrative purposes a selection of six quotes by distinguished scholars is provided below:

- 'Their overall results are in line with Rumelt's results and confirm that both industry and firm efforts are important in shaping profitability' (Henderson \& Mitchell, 1997:6).

- $\quad$ 'Conceptual work by Oliver (1997) stresses the need to combine the RBV and the institutional perspective. The latter concept extending the conventional industry and market characteristics to also include government, society and interfirm relations' (Oliver, 1997:711).

- 'The main conclusion of the paper is that the classical models of strategy and the resource-based strategy definitions are not separate but can offer complementary insight into the company's strategyformulation problematic' (Juga, 1999:16).

- ‘... our results generally support the importance of environment/organization matching and configurational logic in explaining the performance effects ...' (Forte, Hoffman, Lamont \& Brockman, 2000:771).

- 'Practicing strategists have no choice but to deal simultaneously with resource-side issues... and potential demand-side issues' (Priem, 2001:30).

- $\quad$ 'Strategy needs to exhibit external consistency - firm resources need to be matched with environmental opportunities, and internal consistency - a fit between strategy and organizational elements' (Farjourn, 2002:565).

Notwithstanding the above, what still seems to be missing is a description and explanation of the links and relationships between the PBV and the RBV. This paper contends that marketing can perform a major role in facilitating the formulation of overall organisational strategy in an integrative fashion. In this regard Kotler, Jain and Maesimee (2002 xi) note that: 'We hold that marketing should be positioned as the driver of corporate strategy in the digital economy'. The marketing sub-unit is discussed in the next 
section and serves as the basis from which its assimilating capability will be outlined.

\section{Business strategy and the importance of functional units - the role of marketing}

\section{Introduction}

The relationship between business strategy and functional strategies or, in a broader sense, all sub-unit strategies, is important because it concerns resource planning and, in particular, the allocation of resources in accordance with their perceived role (importance) in implementing a given strategy. Different strategies suggest different roles for each sub-unit (Waldersee \& Sheather, 1996:105). Notwithstanding this important relationship between business strategy and sub-unit strategies, very limited understanding appears to exist in this regard. For example:

- '...questions regarding whether the effectiveness of various grand strategies depends on emphasis on different functional activities have not been satisfactorily answered' (Hitt, Ireland \& Palia, 1982:265); and

- '... there has been little examination of the level and determinants of the marketing unit's influence within the firm' (Homburg, Workman \& Krohmer, 1999:1).

Against this brief background the remainder of this section will subsequently address the relative role of marketing in the organisation. First in a general, overall context, followed by an overview of marketing's role within respectively the PBV and the RBV.

\section{The functional role of marketing}

A study by Snow and Hrebiniak (1980) examined the relationship between strategy and distinctive competences, which they used as a proxy for 'functions'. Aggregation of data revealed that General Management was regarded as the most important function, followed by Financial Management and Marketing/Selling (Snow \& Hrebiniak, 1980:326). Hitt, Ireland \& Palia (1982) investigated the impact of four grand strategies (considered to be the label for business level strategy) on the relative importance of organisational functions. Their research ranked Marketing in fourth place, virtually on par (mean 4,47) with Personnel (mean 4,48). The first and second positions were filled by respectively General Management and Government Relations.

Research regarding functional roles and their relative importance appears to be very sketchy and fragmented after the early 1980's and tended to shift towards the concept of power. In marketing, power has been studied most extensively in the more narrow context of distribution channel relationships (Schreuder, 2002). As noted before, little is at present known about the overall influence of marketing in the organisation (Homburg, Workman \& Krohmer, 1999:1).
Furthermore, the issue is still clouded with the debate which was fuelled by Day and Wensley (1983), Day (1992) and Kerin (1992) concerning the question whether marketing's role should be considered within the context of a function (practice) or indeed as a shaper of business strategy (discipline). No conclusive view has yet been agreed upon.

\section{Marketing and the PBV}

The PBV represents an outside - in perspective. As such, the marketing function with its external orientation is considered to provide a natural link with this approach to formulating a business strategy (Oosthuizen, 1997:64). Furthermore, it has long been recognised that '... a distinct trend (exists) in business practice: the integration of marketing planning into the strategic planning process' (Abell \& Hammond, 1979:x:). In this section the relationship between marketing and the Miles and Snow (1978) PBV, the Porter (1985) PBV as well as Covin's (1991) PBV will be referred to.

The Miles and Snow description of the dominant coalitions within the Prospector typology is as follows: '... the Prospector's dominant coalition centres around the marketing and research and development functions' $(1978: 60)$. In the case of the Defender ... 'financial and production experts wield considerable power', and '... marketing ..., ranks well below the controller and production manager in terms of influence ...' (1978:42).

A follow-up study by Snow and Hrebiniak (1980) confirmed that Marketing/Sales and Market Research are relatively more important in the case of the Prospector-typology than for Defenders (Snow \& Hrebiniak, 1980:327). A study by Hambrick (1983) corraborated this finding. Homburg, Workman and Krohmer (1999:4) found that 'Marketing's influence is related positively to the growth rate of the market', the latter condition which they equated to the Prospected strategy. Overall, however, it would appear that the 1993 finding by Slater and Narver (1993:48) that the relationship between the Miles and Snow typologies and a most effective marketing programme still leaves many questions unanswered, is still valid.

Although Porter's value chain identifies Marketing and Sales as one of its primary activities (Porter, 1985:40), no research, as far as can be ascertained, exists which provides a clear and direct link between Porter's generic strategies of cost leadership and differentiation, and marketing. A perusal of related works may, however, suggest that marketing is more important for a differentiation strategy than in the case of cost leadership. In this regard Homburg, Workman and Krohmer (1999:11) found some empirical support that the influence of marketing is significantly higher for a business unit with a differentiation strategy, but not that the influence of marketing is significantly lower for business units with a cost leadership strategy.

The study by Covin (1991) describes entrepreneurial and conservative strategies in terms of finance, marketing and operational criteria but offers no clear indication of the relative importance of these functions. However, it may tentatively be suggested that marketing is probably of a 
relatively greater importance for an entrepreneurial rather than a conservative strategy. This is based upon the finding that, compared to conservative organisations, entrepreneurial organisations offer more extensive customer service/support, offer better product warrantees, and are more concerned about staying in touch with industry and market trends. These findings are supported by similar sentiments expressed by Waldersee and Sheather (1996:109).

In conclusion, the relationship between PBV business strategies and marketing is not at all clear. It becomes even more complex and confusing when specific elements (McDaniel \& Kolari, 1987:23), distinctive marketing competencies (Conant, Mokwa \& Varadarajan, 1990:374) and marketing activities (Oosthuizen, 1997:68) are considered. Also, the vast majority of this PBV research does not address the issue of marketing's role in organisations in less developed countries or emerging market economies (Fahy, Hooley, Cox, Beracs, Fonfara \& Snoj, 2000 and Day, 2000), e.g. Africa. In this regard it has been suggested that marketing should preferably be examined in the context of the resource-based view of the organisation (Day, 2000). This is addressed in the following section.

\section{Marketing and the RBV}

\section{Introduction}

The value of any resource ultimately is realised, directly or indirectly, in the external market-place. From the marketing perspective its contribution is thus to enhance the RBV aim of sustainable competitive advantage by deploying marketing resources towards satisfying targeted customers. However, it would appear that only scant information exists in this regard (Srivastava, Fahey \& Christensen, 2001:778), whilst Kaleka (2002:275) confirms that: 'A review of the general marketing and strategy literature reveals that there is a lack of research on the conceptualization, operationalization and measurement, and empiral validation of sourcesof-advantage classifications'.

In this section the link between the RBV and marketing is first described, followed by a review of marketing related contributions to output performance within the context of the RBV.

\section{Linking the RBV and marketing}

Because the real value of an internal resource is externally determined, it is first necessary to define external, or as it has become known, market-related resources. As can be expected divergent views exist and the major streams are reflected in Table 1 below, followed by a brief description of each view.

\section{Table 1: Market related resources}

\begin{tabular}{lll}
\hline $\begin{array}{l}\text { Market-driven } \\
\text { capabilities }\end{array}$ & Market-based assets & $\begin{array}{l}\text { Market-focused } \\
\text { resources }\end{array}$ \\
\hline $\begin{array}{l}\text { Market sensing } \\
\begin{array}{l}\text { Customer linking } \\
\text { (incl. suppliers) }\end{array}\end{array}$ & $\begin{array}{l}\text { Customer relationships } \\
\text { Partner relationships }\end{array}$ & $\begin{array}{l}\text { Culture } \\
\text { Marketing assets } \\
\text { Marketing capabilities }\end{array}$ \\
\hline
\end{tabular}

Market driven capabilities were identified by Day (1994) as being market sensing and customer linking (incl. suppliers). Market sensing represents the ability of the organisation to learn about customers, competitors, and channel members in order to continuously sense and act on events and trends in present and prospective markets, i.e. a market orientation. Customer linking implies creating and managing close relationships with customers as well as with suppliers.

The concept of market-based assets was proposed by Srivastava, Shervani \& Fahey (1998), and includes customer and partner relationships which aim at customer satisfaction.

Three types of market-focused resources were identified by Hooley, Greenly, Fahy and Cadogan (2001), namely culture, marketing assets and marketing capabilities. Culture implies market orientation whilst marketing assets include aspects like branding, distribution network, information systems and alliances. Marketing capabilities are essentially similar to those previously identified by Day (1994).

From the foregoing it would appear that market-related resources may be classified into three broad categories, namely market orientation (market sensing and culture), relationships (customer and supplier linking and partners), as well as intangible resources (marketing assets). The categories of market orientation and relationships may furthermore be termed capabilities.

Once the organisational market-related resources have been identified, they must be converted or leveraged into value added through the medium of broad or core sociotechnical organisational processes. Again, divergent views exist. According to Srivastava, Shervani and Fahey (1999) three business processes exist, namely a product development management (PDM) process, a supply chain management (SCM) process, and a customer relationship management (CRM) process. Hooley et al. (2001) suggest three key firm processes and contend that marketing (external and internal) per se constitutes a process, as well as innovation and learning. It would appear that Hooley's proposition of core organisational processes is the most generic because his description of marketing as a process includes all three processes identified by Srivastava et al. (1999).

Each one of the core organisational processes must be supported by a number of cross-functional sub-processes. For example, the CRM process identified by Srivastava, et al. (1999:170) is supported, inter alia, by the following subprocesses; learning about product usage and application, developing/executing promotion programs, acquiting/ leveraging information technology/system for customer contact and cross selling and upselling of product service offerings. It is beyond the scope of this paper to identify and analyse sub-processes per se, however, it must be recognised that marketing is one of the functions providing resource-input into these subprocesses. As such it consists of a Portfolio of Marketing Resources which include inter alia tangible marketing assets reflected in the balance sheet as well as complementary assets (brand equity, patents, market oriented culture, distribution networks, etc.) and underlying marketing capabilities (market knowledge, 
customer data base, marketing know-how, CRM skills, innovative abilities, social or networking ties).

The link between marketing and the RBV has been described as 'a goodness of fit between marketing realities and the assumptions of RBV' (Srivastava et al., 2001:778). In its contribution to the RBV marketing has a dual character, first to infuse a marketing perspective (market orientation) into every subprocess (marketing as a discipline), and secondly to infuse this perspective through the medium of individual marketing tasks or activities (marketing as a practice).

\section{The RBV and marketing-related output performance}

The strategic importance of marketing resources and capabilities lies in their demonstrable contribution to creating superior output performance. This value added by marketing resources will be discussed in terms of market output and financial output.

Market output approaches consider measures of customer satisfaction to establish yardsticks of customer value added. In this regard Aaker (1991:16) identified five 'brand assets': brand loyalty, name awareness, perceived quality, brand associations and other propriety brand assets. Srivastava et al. (1998:8) measures market performance in terms of faster market penetration, price and share premiums, extentions, sales/service costs and loyalty/retention. These appear to be very similar in characteristics to what Aaker (1991:46) described as strategic values underlying his 'brand assets'. Srivastava et al. (2001:784) suggest four core dimensions of customer value, namely attributes, benefits, attitudes and network effects. Generally, there appears to be a confusing overlap between the parameters and content of the various market output approaches.

Financial output measures of customer satisfaction revolve around brand equity and shareholder value, i.e. the financial consequences of the implementation of marketing resources and capabilities. Brand equity recognises marketing expenditures as a capital investment, and not as an operating expense. A popular approach to calculating brand equity is the well-known Interbrand brand-valuation (Perrier, 1997). Shareholder returns assess the impact of marketing activities on shareholder value. It demonstrates how market-based assets increase shareholder value by accelerating and enhancing cash flows, lowering the volatility and vulnerability of cash flows, and increase the residual value of cash flows (Srivastava, et al., 1998).

It is not considered that the marketing related measures outlined in the previous paragraphs are necessarily exclusive to the RBV. Hence, for the purposes of this paper, it will not further be elaborated upon.

\section{Concluding comments}

In the foregoing the relationship between the PBV and RBV on the one hand, and marketing on the other, were outlined. In this regard the uncertainties and divergent approaches with regard to the relative importance, conceptualisation, content and implementation of marketing strategy may in all probability be attributed to the fact that it appears to be frozen within either a market-based or a resource-based view, instead of a combined view of business strategy. This perceived shortcoming is addressed in the next section where a framework is proposed for an integrative analysis of business and marketing strategies.

\section{A proposed framework for an integrative analysis of business and marketing strategies}

\section{Introduction}

The major variables and their relationships discussed in previous sections of this paper, are shown in Diagram 2, and briefly recapped.

Both the PBV and the RBV endeavour to achieve competitive advantage and thus deliver above-averageoutput performance to the organisation. How this is achieved, differs widely. The PBV examines the External Environment and, via the application of the Conventional Value Chain positions its Business Strategy, and by implication also the resultant Functional Strategies, to best fit with this environment. The functional marketing strategy is embodied in the Conventional Marketing Plan and aims at constructing, implementing and controlling the Marketing Value-delivery Process.

The RBV also examines the External Environment but with a view to identify Market Related Resources. From here onwards the RBV displays an internal only character by emphasing an Activity Based System in constructing Core Processes and supporting Cross-Functional Prosseses in order to deliver the required Market Related Resources. A Portfolio of Marketing Resources injects into the Cross Functional Processes. To date no clear link seems to have been made between the Portfolio of Marketing Resources and the Marketing Value-delivery Process.

Whilst it is today generally accepted that the PBV and the RBV have a complementary responsibility in business strategy formulation, this integration has not yet clearly been articulated. It is believed that marketing could probably play a major reconciliatory role in this regard, currently reflected as in Diagram 2. How this could conceivably be effected is the topic of the next section, 'The mission approach to marketing'.

\section{The mission approach to marketing}

It could be said that the Conventional Marketing Plan (PBV) displays a silo-approach which is essentially developed around the '4Ps' (Product.Price.Place.Promotion) or some configuration thereof. This 'functional' approach does not necessarily recognise that marketing excellence cuts across these activities and should thus rather be process driven. As such it will provide a conceptual link with the RBV and may be achieved by adopting the mission approach to marketing. This approach was first employed in an effort to overcome the divergence between marketing and financial strategies (Wilson, 1999:69) and is believed to have clear potential and benefits in achieving the same for the PBV and RBV in terms of marketing. 


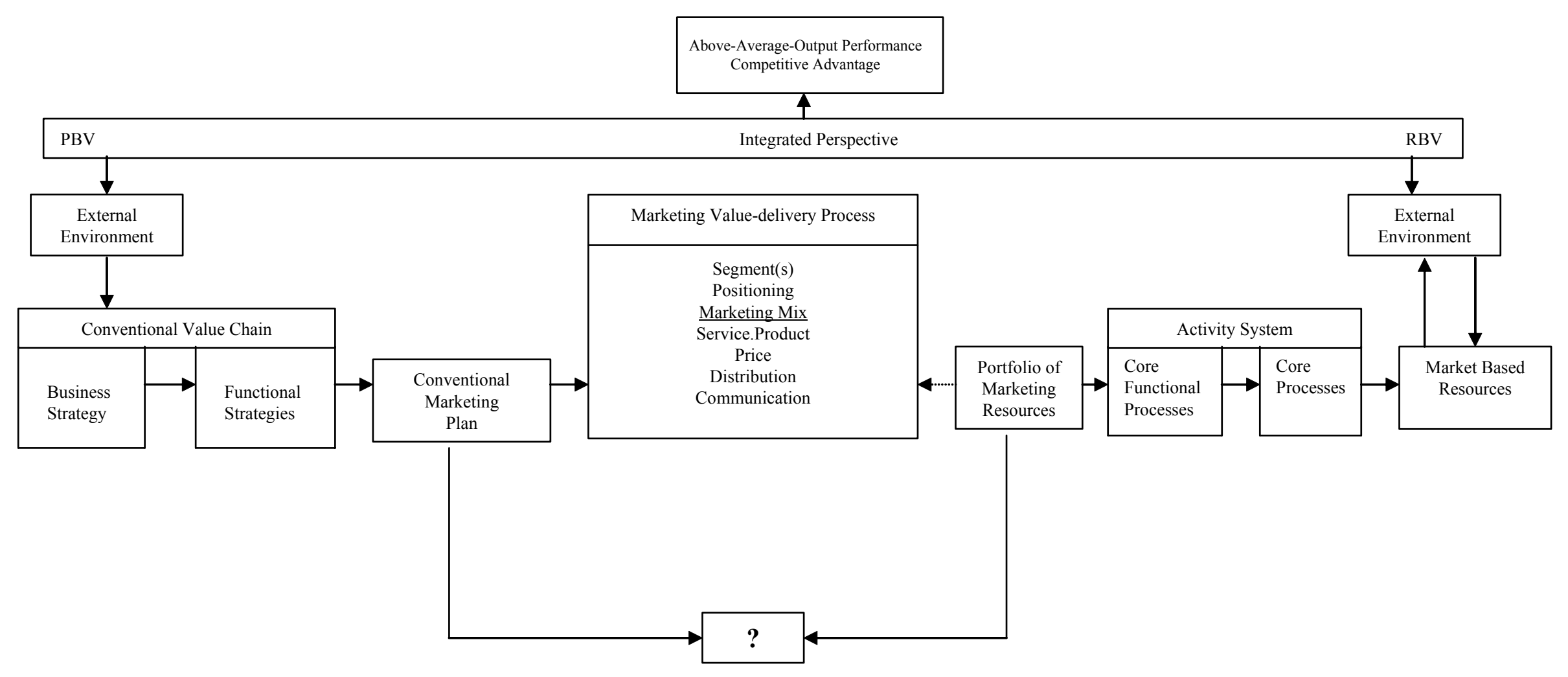

Diagram 2: The relationship between business strategy and marketing strategy 
A mission in this context may be defined as the provision of a product (or service) to a particular customer (horisontal) and to superimpose (vertical) over that the functional flows, to produce a marketing missions matrix. See Diagram 3 below which clearly captures the development of a marketing process approach.

In the next section processes in marketing will be addressed to be followed by a systemic perspective of marketing and re-engineering in marketing.

\section{Processes in marketing}

A process is a set of activities that, taken together, contribute to creating value for the customer and must be done successfully over and over in order for any marketing organisation to survive and prosper (Hammer \& Champy, 1993:3; Stern, 1966:8). Examples of marketing processes would include: new product development, channel management, physical delivery processes and order getting. Process-analysis in research on marketing appears to be very fragmented in itself and tends to be rather incorporated into a broader discussion of marketing systems.

\section{A systemic perspective of marketing}

A systemic approach to marketing apparently emerged as early as the 1960s when efforts were made to apply marketing science to selected marketing areas (Simon, 1994:29), most notable was that of Stasch (1969). In 1976 Stern published a landmark book in this regard and proposed a Total Marketing System (Stern, 1976:112). The systems application has subsequently found great favour and application in the marketing of services (Shostack, 1987, in Lovelock, 1991:147) but, unfortunately, not so for physical goods or marketing in a more general context.
This is to be regretted because modern technology not only makes the systems approach possible but offers many supporting techniques which may greatly enhance marketing decision-making. Some of these include expert marketing systems (Duan \& Burrel, 1997), econometric and diffusion models in marketing (Simon, 1994) and analytical decision support tools (Mahmoud, \& Rice, 2001).

However, marketing operates in an extremely turbulent, global and complex environment. As such it involves high uncertainty, a loose causal structure, and incomplete and dispersed knowledge. Most marketing decision-making and problem-solving tasks seem to be semi-structured or even unstructured (Duan \& Burrel, 1997:2-3). As a result, can it be reasonably expected that a systemic perspective may add any value? Indeed, and on the contrary, the very existence of complexity calls for more scientific, rational and systematic methods of marketing decision-making (Moutinhou, Goode \& Davies, 1998:1).

A recent study (Stratis \& Powers, 2001) investigated the relationship between Structured Strategic Marketing Planning (sophisticated, formalised, written, long-range) and Financial Output Performance (risk-adjusted market return) and concluded that: 'The results show ... that strategic market planning was significant at the 0,002 level indicating that strategic market planning and risk-adjusted market returns are significantly related ... structured strategic planning-based firms outperform firms with less robust forms of planning' (Stratis \& Powers, 2001:174). A similar conclusion was reached for small and medium sized organisations (O'Regan \& Ghobadian, 2001). Clearly, a structured approach to marketing is still valid in the New Economy. Such a structured, systemic approach raises the question of the application of re-engineering to marketing.

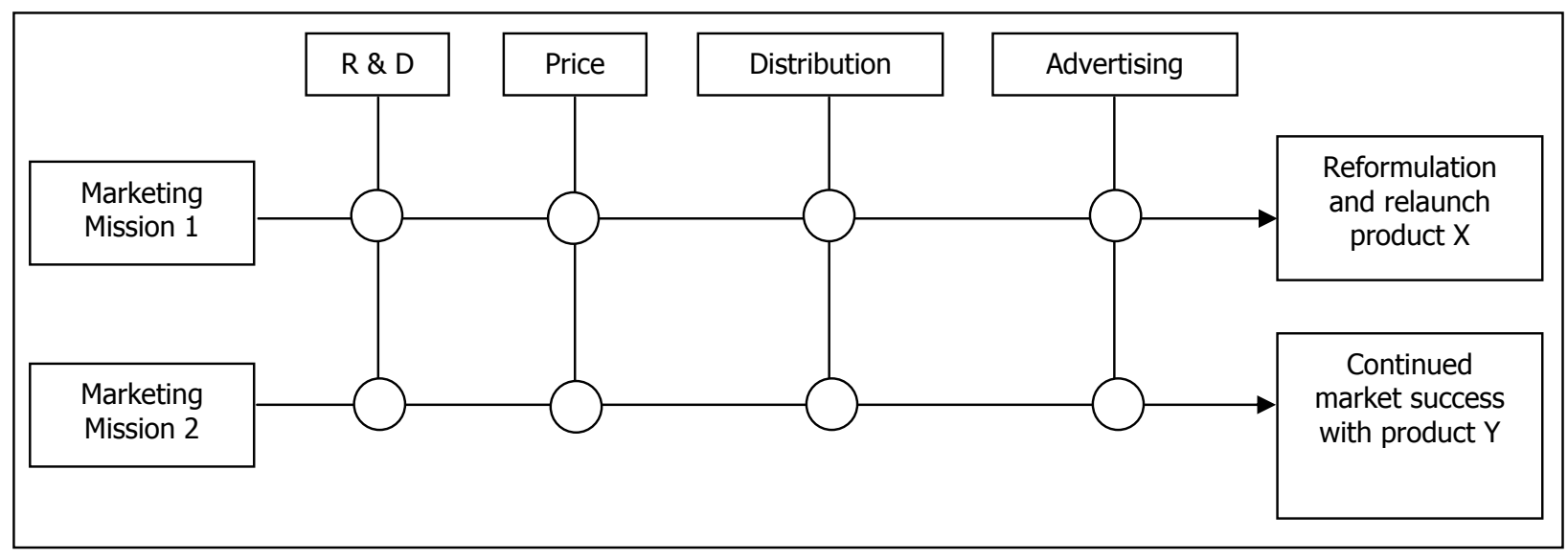

Diagram 3: $\quad$ Example of marketing mission approach 


\section{Re-engineering and marketing}

'Business reengineering means starting all over, starting from scratch' (Hammer \& Champy, 1993:2). From the previous sections it has became apparent that marketing should be starting from scratch and re-engineer from the old conventional way to a systemic approach. Research has shown that a very close relationship exists between the philosophies of marketing and that of re-engineering (Aurand, Schoenbachler \& Schroeder, 2001:134). They may in fact be two parts of one construct. Marketing processes are subsequently obvious candidates for reengineering and some examples of re-engineered marketing processes are sales, customer service, order fulfillment, distribution and product development (Aurand, Schroeder \& Yaney, 2000:27).

Generally speaking, however, it has been found that 'although marketers buy into the rhetoric of reengineering, they do not apply it wholeheartedly' (Aurand, Shoenbackler \& Gordon, 1996:24).

\section{Summary}

The integration between the PBV and the RBV can be facilitated by introducing the mission approach to marketing. This redesigns the conventional marketing plan to also include processes. A process application to marketing results in the development of a systemic approach to marketing. This structured and rational approach enables the application of analytical techniques to marketing. These have been found to add value under conditions of external turbulence. Re-engineering also offers optimalisation opportunities but has not yet readily been accepted into marketing.

\section{Findings}

The major findings of this paper may be summarised as follows:

- A tautology does not exist between the PBV and RBV. Both aim at achieving competitive advantage and delivering above-average-output performance. Indeed, a reciprocal relationship exists between the external environment and the organisational resources. Nevertheless, what sill seems to be missing is a description and explanation of the links and relationships between the two approaches.

- The relationship between business strategies and functional strategies, particularly with regard to their relative importance, is not clear. In the case of the marketing function the issue is furthermore clouded by the debate that marketing be seen either as a function (practice) or as a shaper of business strategy (discipline). No consensus seems to exist.

- The uncertainties with the conceptualisation, content and implementation of marketing strategy may in all probability be attributed to the fact that it appears to be frozen within either a market-based or a resource-based view, instead of a combined view of business strategy.
- A conceptual framework has been proposed which combines the PBV and RBV business approaches into one integrated marketing mission approach. As such the marketing function may perform a major reconciliatory role in facilitating the formulation of overall organisation strategy in an integrative fashion.

- The marketing mission approach cuts across the traditional elements of a conventional marketing plan and introduces the concept of marketing processes. This enables the development of an overall systemic approach to marketing and, in turn creates the possibility for the application of analytical techniques and re-engineering in marketing systems. The value added by utilising structured and formalised marketing systems during turbulent times has been shown.

\section{Conclusion and the way forward}

This paper has reiterated the symbiotic relationship that exists between business strategy and marketing strategy. A framework was proposed in this regard and provides the cornerstone for the development of a systemic approach to marketing, utilising analytical tools. Not only do existing conceptual models in this context tend to be fragmented, but empirical research of this nature is scant, particularly for developing economies and apparently non-existent in the South African context.

The above implies clear research and teaching responsibilities for the future:

The conceptual framework should be subjected to further development and refinement. In this regard two suggestions may be considered:

- $\quad$ The principles of the Balanced Scorecard (Kaplan \& Norton, 1996) may be applied to marketing decisionmaking per se, and thus integrated into the overall strategic system of any organisation using this particular framework. As far as can be ascertained only the ICSB Research Unit at Erasmus University, Rotterdam, has accomplished research in this direction (www.icsb nl/publications/abstracts/absmbscboek htm)

- $\quad$ The proposed framework is essentially of a planning nature. It should be extended to also incorporate aspects of marketing controls but should, however, go beyond any conventional metrics (e.g. sales, market share, profitability, etc.) towards a systemic model. An attempt in this direction was made by Bonoma and Clark (1988) with their Marketing Performance Assessment (MPA)-Model which combines the effectiveness (external considerations) and the efficiency (internal resources and skills) strands in marketing performance assessment.

The conceptual framework must be empirically validated in order to gain predictive or managerial acceptance. At this stage and level of model-development a fine-grained methodology would probably be most appropriate, 'Finegrained treatments of strategy benefit from their attention to important details that help researchers characterize the 
complexities of strategy formulation' (Harrigan, 1983:398). It is furthermore suggested that the concept of Theoretical Sampling may be most suitable to this research (Coyne, 1997).

Once validated the framework must be applied to South Africa and preferably also other Southern African countries in order to establish its generalisability to developing economies in general. A coarse-grained approach is suggested. For a South African application it would, furthermore, be advantageous to endeavour to link the conceptual model to relevant criteria in the South African Excellence Model (SAEM), e.g. customer and market focus, resources and information management, processes, customer satisfaction and supplier and partnership performance (www.saef.co.za). As such it could make a contribution towards enhancing the competitiveness of local organisations.

Marketing and Analytical Science are usually taught as two totally separate subjects at most universities and business schools. Advanced marketing texts often include some reference to quantification, e.g. 'The theory of effective marketing-resource allocation' and 'Statistical methods for future demand projection' (Kotler, 1997:Appendices 1 \& 2), whilst 'Quantitative Colleagues' normally assure their marketing counterparts that they 'use marketing examples in their classes'. This attitude, from both sides, is not acceptable given the trends in strategy and marketing. Curriculum should be adjusted to provide for a combined teaching of marketing and quantitative analyses. It could be done and is in the long-term interest of both disciplines.

\section{Acknowledgements}

The author wishes to thank Prof. M. Leibold and Prof. A. Archer for their helpful comments with the development of this paper. The responsibility remains that of the author.

\section{References}

Aaker, D.A. 1991. Managing brand equity. New York: The Free Press, p. 299.

Abell, D.F. \& Hammond, T.S. 1979. Strategic market planning. Englewood Cliffs, N.J.: Prentice/Hall International, Inc., p. 527.

Amit, R. \& Schoemaker, P.J.H. 1993. 'Strategic assets and organizational rent', Strategic Management Journal, 14:3346.

Andrews, K.R. 1971. The concept of corporate strategy. Homewood, Illionois: Dow Jones-Irwin, Inc., p. 245.

Ansoff, I. 1965. Corporate strategy. London: Penguin Books, p. 284.

Aurand, T.W., Schoenbachler, D.D. \& Gordon, G.L. 1996. 'Reengineering and the marketing function: Integration of theory and practice', Journal of Product \& Brand Management, 5(3):6-24.
Aurand, T.W. \& Schoenbachler, D.D. \& Schroeder, B. 1999. 'Perceived involvement in reengineering and the marketing concept: Theory foundations and practitioner perceptions', Journal of Marketing, Spring: 124-135.

Aurand, T.W., Schroeder, B.L. \& Yaney, J. 2000. 'Reengineering: An essential element of today's marketing curriculum', Marketing Education Review, 10(1):25-32.

Barney, J. 1991. 'Firm resources and sustained competitive advantage', Journal of Management, 17(1):99-120.

Barney, J.B. 2001. 'Is the resource-based 'view' a useful perspective for strategic management research? Yes', Academy of Management Review, 26(1):41-56.

Barney, J., Wright, M. \& Ketchen, D.J. 2001. 'The resourcebased view of the firm: Ten years after 1991', Journal of Management, 27:625-641.

Bonoma, T.V. \& Clark, B.H. 1988. Marketing performance assessment. Boston, Massachusetts: Harvard Business School Press, p. 202.

Boyd, H.W., Walker, O.C. \& Larréché, J-C. 1998. Marketing management. $3^{\text {rd }}$ Edition. Boston, Massachusetts: IrwinMcGraw-Hill, p. 545.

Campbell, D., Stonehouse, G. \& Houston, B. 2000. Business strategy. Oxford: ButterworthHeineman, p. 333.

Castanias, R.P. \& Helfat, C.E. 1991. 'Managerial resources and rents', Journal of Management, 17(1):155-171.

Clark, C.J. \& Brennan, K. 1990. 'Four portfolio analyses'. In Campbell, A. \& Luchs, K.S. 1998. Strategic synergy. $2^{\text {nd }}$ Edition. London: International Thomson Business Press, p. 340 .

Collis, D.J. \& Montgomery, C.A. 1995. 'Competing on resources: Strategy in the 1990s', Harvard Business Review, 73(4):118-129.

Conant, J.S., Mokwa, M.P. \& Varadarajan, P.R. 1990. 'Strategic types, distinctive marketing competencies and organizational performance: A multiple measure-based study', Strategic Management Journal, 11:365-383.

Covin, J.G. 1991. 'Entrepreneurial versus conservative firms: A comparison of strategies and performance', Journal of Management Studies, 28(5): 439-461.

Coyne, I.T. 1997. 'Sampling in qualitative research. Purposeful and theoretical sampling; merging or clear boundaries', Journal of Advanced Nursing, 26:623-630.

Das, T.K. \& Teng, B. 2000. 'A resource-based theory of strategic alliances', Journal of Management, 26(1):31-61.

Day, G.S. 1992. 'Marketing's contribution to the strategy dialogue', Journal of the Academy of Marketing Science, 29 (Fall):323-329. 
Day, G.S. 1994. 'The capabilities of market-driven organizations', Journal of Marketing, 58:37-52.

Day, G.S. 2000. 'Strategy in emerging economies', Academy of Management Journal, 43(3): 249-289.

Day, G.S. \& Wensley, R. 1983. 'Marketing theory with a strategic orientation', Journal of Marketing, 47(Fall):79-89.

Dierckx, I. \& Cool, K. 1989. 'Asset stock accumulation and sustainability of competitive science advantage', Management Science, 35(12):1504-1511.

Duan, Y. \& Burrell, P. 1997. 'Some issues in developing expert marketing systems', Journal of Business \& Industrial Marketing, 12(2):149-162.

Eisenhardt, K.M. \& Martin, J.A. 2000. 'Dynamic capabilities: What are they?', Strategic Management Journal, Special Issue, October-November, 21:1105-1121

Fahey, J., Hooley, G., Cox, T., Beracs, J., Fonfara, K. \& Snoj, B. 2000. 'The development and impact of marketing capabilities in Central Europe', Journal of International Business Studies, 31 (1):63-81.

Farjoun, M. 2002. 'Towards on organic perspective on strategy’, Strategic Management Journal, 23:561-594.

Fish, G.G. 1961. 'Line-staff is obsolete', Havard Business Review, 39(5):67-79.

Forté, M., Hoffman, J.J., Lamont, B.T. \& Brockman, E.N. 2000. 'Organization form and environment: An analysis of between-form and within-form responses to environmental change', Strategic Management Journal, 21:753-773.

Gagnon, S. 1999. 'Resource-based competition and the new operations strategy', International Journal of Operations, 19(2):125-138.

Hambrick, D.C. 1983. Some tests of the effectiveness and functional attributes of Miles and Snow's strategic types. Acadamy of Management Journal, 26(1):5-26.

Hammer, M. \& Champy, J. 1993. Reengineering the corporation. London: Nicholas Brealey Publishing, p. 223.

Harrigan, K.R. 1983. 'Research methodologies for contingency approaches to business Strategy', Academy of Management Review, 8(3):398-405.

Henderson, R. \& Mitchell, W. 1997. 'The interactions of organizational and competitive influences on strategy and performance', Strategic Management Journal, 18 (Summer Special Issue): 5-14.

Hitt, M.A. \& Ireland, R.D. 1985. 'Corporate distinctive competence, strategy, industry and performance', Strategic Management Journal, 6:273-293.

Hitt, M.A., Ireland, R.D. \& Palia, K.A. 1982. 'Industrial firm's grand strategy and functional importance: Moderating effects of technology and uncertainty', Academy of Management Journal, 25(2):265-298.

Homburg, C., Workman, J.P. \& Krohmer, H. 1999. 'Marketing's influence within the Firm', Journal of Marketing, 63 (April):1-17.

Hooley, G., Greenley, G., Fahy, J. \& Cadogan, J. 2001. 'Market-focused resources, competitive positioning and firm performance', Journal of Marketing Management, 17:503520 .

Johansson, H.J., McHugh, P., Pendlebury, A.J. \& Wheeler, W.A. 1993. Business process reengineering. Chichester: John Wiley \& Sons, p. 241.

Juga, J. 1999. 'Generic capabilities: Combining positional and resource-based views for strategic advantage', Journal of Strategic Marketing, 7:3-18.

Kaleka, A. 2002. 'Resources and capabilities driving competitive advantage in export markets: guidelines for industrial exporters', Industrial Marketing Management, 31:273-283.

Kaplan, R.S. \& Norton, D.P. 1996. 'Using the Balanced Scorecard as a strategic management system', Harvard Business Review, January - February:75-85.

Kerin, R.A. 1992. 'Marketing's contribution to the strategy dialogue revisited', Journal of the Academy of Marketing Science, 20(4):331-334.

King, A.W. \& Zeithaml, C.P. 2001. 'Competencies and firm performance: Examining the causal ambiguity paradox', Strategic Management Journal, 22:75-99.

Kotler, P. 1997. Marketing management. New Jersey: Prentice-Hall International, Inc., p. 789.

Kotler, P., Jain, D.C. \& Maesimee, S. 2002. Marketing moves. Boston, Massachusetts: Harvard Business School Press, p.191.

Long, C. \& Vickers-Koch, M. 1995. 'Using core capabilities to create competitive Advantage', Organizational Dynamics, Summer: 1995. In Thompson, A.A. \& Strickland, A.J. 1998. Creating and implementing strategy. $10^{\text {th }}$ Edition. Boston, Massachusetts: IrwinMcGraw-Hill, p. 635.

Lengnick-Hall, C.A. \& Wolff, J.A. 1999. 'Similarities and contradictions in the core logic of three strategy research streams', Strategic Management Journal, 20:1109-1132.

Mahmoud, E. \& Rice, G. 2001. 'Use of analytical techniques in international marketing', International Marketing Review, Autumn: 7-13.

Marsden, A. 1998. 'Strategic management: Which way to competitive advantage?', Management Accounting, 76(1):32-38. 
McDaniel, S.W. \& Kolari, J.W. 1987. 'Marketing strategy implications of the Miles and Snow strategic typology', Journal of Marketing, 51:19-30.

McGahan, A.M. \& Porter, M.E. 1997. 'How much does industry matter, really?', Strategic Management Journal, 18 (Summer Special Issue):15-30.

Medcof, J.W. 2000. 'The resource-based view and transnational technology strategy', Journal of High Technology Management Research, 11(1):59-75.

Miles, R.E. \& Snow, C.C. 1978. Organizational strategy, structure, and process. New York: McGraw-Hill Book Company, p. 274.

Moutinhou, L., Goode, M. \& Davies, F. 1998. Quantitive analysis in marketing management. Chichester: John Wiley \& Sons, p. 331.

Oliver, C. 1997. 'Sustainable competitive advantage: Combining institutional and resource-based views', Strategic Management Journal, 18(9):697-713.

Oosthuizen, H. 1997. 'An evaluation of the relevance of the Miles \& Snow strategic typology under present-day conditions of major environmental uncertainty - the emperor's new clothes or a paradigm shift?', South African Journal of Business Management, 28(2):63-72.

Oosthuizen, H. 2000. 'A competence-based approach to strategy', USB-News, 1:10-11.

O'Regan, N. \& Ghobadian, A. 2001. 'Does formal strategic planning enhance performance?' Paper read at $21^{\text {st }}$ Annual International Conference Strategic Management Society, October 21-24, San Francisco, California, USA.

Peng, M.W. 2001. 'The resource-based view and international business', Journal of Management, 27:803829.

Perrier, R. 1997. (Ed.). Brand valuation. London: Premier Books, p. 236.

Peteraf, M.A. 1993. 'The cornerstones of competitive advantage: A resource-based view', Strategic Management Journal, 14:179-191.

Peters, T.J. \& Waterman, R.H. 1982. In search of excellence. New York: Warner Books, p. 360.

Pettus, M.L. 2001. 'The resource-based view as a developmental growth process: Evidence from the deregulated trucking industry', Academy of Management Journal, 44(4):878-896.

Pollalis, Y. \& Grant, J.H. 1994. 'Information resources and corporate strategy development', Information Strategy: The Executive's Journal, 11(1):12-28.
Poppo, L. \& Weigelt, K. 2000. 'A test of the resource-based model using baseball free agents', Journal of Economics \& Management Strategy, 9(4):585-615.

Porter, M.E. 1996. 'What is strategy?', Harvard Business Review, November - December: 61-78.

Porter, M. 1985. Competitive advantage. New York: The Free Press, p. 557.

Prahaland, C.K. \& Hamel, G. 1990. 'The core competence of the corporation', Harvard Business Review, MayJune:79-91.

Priem, R.L. 2001. 'Tautology in the resource-based view and the implications of externally determined resource value: Further comments', Academy of Management Review, 26(1):57-67.

Rouse, M.J. \& Daellenbach, U.S. 2002. 'More thinking on research methods for the resource-based perspective', Strategic Management Journal, 23:963-967.

Rugman, A.M. \& Verbeke, A. 2002. 'Edith Penrose's contribution to the resource based view of strategic management', Strategic Management Journal, 23(8):769780 .

Rumelt, R.P. 1981. 'Towards a strategic theory of the firm.' In Lamb, R.B. 1984. Competitive strategic management. Englewood Cliffs, N.J.: Prentice-Hall, Inc., p. 763.

Schreuder, F.A. 2002. 'An investigation into global distribution systems in the crop protection industry and the development of distribution system management models for particular application in South African and Australia'. Unpublished PhD dissertation, University of Stellenbosch.

Segev, E. 1989. 'A systematic comparative analysis and synthesis of two business level strategic typologies', Strategic Management Journal, 10:487-505.

Shostack, G.L. 1987. 'Service positioning through structural change'. In Lovelock, C.H. 1991. Services marketing. $2^{\text {nd }}$ Edition. London: Prentice-Hall International, Inc., p. 526.

Simon, H. 1994. 'Marketing science and the ivory tower', Business Strategy Review, Spring: 29-45.

Slater, S.F. \& Narver, J.C. 1993. 'Product-market strategy and performance: An analysis of the Miles and Snow strategy types', European Journal of Marketing, 27(10): 3351.

Snow, C.C. \& Hrebiniak, L.G. 1980. 'Strategy, distinctive competence, and organizational performance', Administrative Science Quarterly, 25:317-335.

Srivastava, R.K., Fahey, L. \& Christensen, H.K. 2001. 'The resource-based view and marketing: The role of marketbased assets in gaining competitive advantage', Journal of Management, 27:777-802. 
Srivastava, R.K., Shervani, T.A. \& Fahey, L. 1999. 'Marketing, business processes and shareholder value: An organizationally embedded view of marketing activities and the discipline of marketing', Journal of Marketing, 63 (Special Issue): 168-179.

Srivastava, R.K., Shervani, T.A. \& Fahey, L. 1998. 'Marketbased assets and shareholder value: A framework for analysis', Journal of Marketing, 62 (January): 2-18

Stasch, S.F. 1969. 'Systems analysis for controlling and improving marketing Performance', Journal of Marketing, 33 (April):12-19.

Stern, M.E. 1966. Marketing planning. New York: McGraw-Hill book Company, p. 153.

Stockport, G.J. \& Chaddad, F. 2001. 'Resource-based research: From 1984 to 2000 and beyond', paper presented at the $21^{\text {st }}$ Annual Strategic Management Society Conference: Old Truths and New Insights, San Francisco, October 21-24.

Stratis, G. \& Powers, T.L. 2001.'The impact of multiple strategic marketing processes on financial performance', Journal of Strategic Marketing, 9:165-191.

Teece, D.J., Pisano, G. \& Shuen, A. 1997. 'Dynamic capabilities and strategic Management', Strategic Management Journal, 18(7):509-533.

Thompson, A.A. \& Strickland, A.J. 2001. Strategic management. Boston: McGraw -Hill Irwin, p. 440.

Valentin, E.K. 2001. 'SWOT analysis from a resource-based view’, Journal of Marketing, 9(2):54-69.

Waldersee, R. \& Sheather, S. 1996. 'The effects of strategy type on strategy implementation actions', Human Relations, 49(1):105-122.

Wernerfelt, B. 1984. 'A Resource-based view of the firm', Strategic Management Journal, 5:171-180.

Wilson, R.M.S. 1999. Accounting for marketing, London: International Thompson Business Press, p. 167.

www.icsb nl/publications/abstracts/absmbscboek htm

$\underline{\text { www.saef.co.za }}$ 